\title{
Hemorrhoidectomy with Harmonic Scalpel vs Conventional Hemorrhoidectomy
}

\author{
Hana Alhomoud ${ }^{1}$, Mohamed Mohsen ${ }^{2}$, Salah Termos ${ }^{3}$
}

\begin{abstract}
Background:Hemorrhoidal disease is one of the most frequently encountered anorectal conditions in the clinical practice. A variety of instruments including circular staplers, harmonic scalpel, laser, and bipolar electrothermal devices are currently used when performing hemorrhoidectomy grades III and IV.

Objective: This study compares outcomes between hemorrhoidectomy performed with harmonic scalpel and conventional methods.

Materials and methods: A prospective randomized study of consecutive 50 patients who underwent hemorrhoidectomy between January 2017 and October 2017. Patients were randomly enrolled in two different groups. Group I consisted of 25 patients who underwent hemorrhoidectomy using an ultrasonic scalpel device (harmonic) and group II with 25 patients who had conventional hemorrhoidectomy.

Results: The patients' demographics data and clinical characteristics were similar in both groups. The harmonic group had a shorter operation time, less postoperative pain, less postoperative bleeding, and shorter hospital stay.

Conclusion: Harmonic scalpel hemorrhoidectomy appears to be a better procedure for symptomatic grades III and IV hemorrhoids with ease of operating due to less bleeding, less postoperative pain, and patient acceptance. Long-term follow-up with larger scale studies is required.

Keywords: Harmonic scalpel, Hemorrhoids, Milligan-Morgan procedure.

World Journal of Laparoscopic Surgery (2018): 10.5005/jp-journals-10033-1352
\end{abstract}

\section{INTRODUCTION}

Hemorrhoidectomy is the standard treatment for patients with grade III or IV hemorrhoids. ${ }^{1}$ Milligan and Morgan open hemorrhoidectomy or Ferguson closed hemorrhoidectomy is still the gold standard for surgical treatment of symptomatic hemorrhoids. ${ }^{2}$ However, both are associated with significant postoperative pain and complicaions such as urinary retention, constipation, postoperative bleeding, anal incontinence, and anal stenosis. $^{3}$

As a result, various types of surgical equipment have been introduced to overcome the postoperative pain and bleeding.

The operative procedures vary from conventional cautery dissection to vessel-sealers, harmonic scalpels, laser hemorrhoidectomy, and stapling devices.

A harmonic scalpel is a device that simultaneously cuts and coagulates tissues by producing a vibration of $55.5 \mathrm{kHz}$. When compared with conventional electrosurgical devices, this ultrasonic cutting and coagulating device has advantages such as causing minimal lateral tissue injury $1-3 \mathrm{~mm}$ wide, less fumes, more localized impact, ${ }^{4}$ better hemostasis, less stimulation to neuromuscular tissues, and local control of the surgical site compared to a hemorrhoidectomy performed with surgical scissors or monopolar electric cautery. ${ }^{5}$

The aim of this study was to analyze and compare between conventional hemorrhoidectomy and hemorrhoidectomy performed with harmonic scalpel.

\section{Materials and Methods}

A prospective randomized study involving 50 patients who were operated for symptomatic grade III and IV hemorrhoids, in Sabah Hospital, Kuwait, between January 2017 and October 2017.
1,2Department of Surgery, Al-Sabah Hospital, Alyarmouk, Kuwait

${ }^{3}$ Department of Surgery, Amiri Hospital, Kuwait city, Kuwait

Corresponding Author: Hana Alhomoud, Department of Surgery, Al-Sabah Hospital, Alyarmouk, Kuwait, Phone: +965 99227676, e-mail: hana_alhomoud@hotmail.com

How to cite this article: Alhomoud $H$, Mohsen $M$, et al. Hemorrhoidectomy with Harmonic Scalpel vs Conventional Hemorrhoidectomy. World J Lap Surg 2018;11(3):121-123.

Source of support: Nil

Conflict of interest: None

Patients were randomized into two groups: group I consist of 25 patients who had hemorrhoidectomy using harmonic scalpel and group II with 25 patients who had conventional hemorrhoidectomy.

All patients underwent preoperative lab tests, chest X-rays, electrocadiography, and urinanalysis and were admitted to the hospital the day before surgery. All patients were fully informed about the procedure and possible complications, and a written consent was given. All patients had a glycerin enema the night before surgery and prophylactic antibiotics were injected before surgery.

The outcome factors including intraoperative bleeding, postoperative pain (on VAS scale), postoperative bleeding, urinary retention, and anal stenosis were compared between the two groups.

All data were collected and analyzed using SPSS 2 version. Chi-square test and student $t$ test were performed for comparison of groups. A $p$ value $<0.05$ was considered as statistically significant.

() The Author(s). 2018 Open Access This article is distributed under the terms of the Creative Commons Attribution 4.0 International License (https://creativecommons. org/licenses/by-nc/4.0/), which permits unrestricted use, distribution, and non-commercial reproduction in any medium, provided you give appropriate credit to the original author(s) and the source, provide a link to the Creative Commons license, and indicate if changes were made. The Creative Commons Public Domain Dedication waiver (http://creativecommons.org/publicdomain/zero/1.0/) applies to the data made available in this article, unless otherwise stated. 


\section{Results}

The mean age of patients who underwent harmonic scalpel hemorrhoidectomy and conventional hemorrhoidectomy was $30 \pm 9.2$ years and $35.8 \pm 5$ years, respectively. The mean hospital stays were $1 \pm 0.1$ days for group I and $2.5 \pm 0.6$ days for conventional hemorrhoidectomy.

The mean operating time of the harmonic scalpel group was $10 \pm 0.7$ minutes and $20.5 \pm 2.2$ minutes for conventional hemorrhoidectomy $(p<0.05)$. This difference was statistically significant and is shorter in the harmonic group.

There was no significant difference between group I and group II in terms of the number of excised hemorrhoids.

In the conventional group, one patient had minor bleeding on postoperative day 1; conversely in the harmonic group, no bleeding occurred for any patients.

One patient had urinary retention in group II and none from group I, the harmonic scalpel group.
No anal stenosis or incontinence was noted in either group.

The postoperative pain scores were $5.4 \pm 0.5$ vs $6.8 \pm 1.2$ on post operative day 1 (POD1) and $1.5 \pm 1.2$ vs $4.1 \pm 0.6$ on POD3 in the harmonic scalpel group and conventional hemorrhoidectomy group, respectively; these differences were statistically significant $(p<0.05)$ Table 1 and Figure 1.

\section{Discussion}

Hemorrhoidectomy is one of the most common surgical procedures performed in Al-Sabah Hospital, Kuwait.

Hemorrhoidectomy is the most effective and definitive treatment for symptomatic hemorrhoids.

Traditional hemorrhoidectomy techniques, including a Milligan-Morgan open hemorrhoidectomy and a Ferguson closed hemorrhoidectomy, are known to be very effective and appropriate treatment for grade III and IV hemorrhoids. However, the traditional surgical methods are accompanied by complications such as

Table 1: Outcome of harmonic scalpel hemorrhoidectomy vs conventional hemorrhoidectomy

\begin{tabular}{|c|c|c|c|}
\hline Characteristic & $\begin{array}{l}\text { Harmonic scalpel group } \\
\text { (25 patients) I group }\end{array}$ & $\begin{array}{l}\text { Conventional hemorrhoidectomy } \\
\text { group ( } 25 \text { patients) II group }\end{array}$ & $p$ value \\
\hline Age & $30.1 \pm 9.2$ & $35.8 \pm 5$ & \\
\hline Mean hospital stay (days) & $1 \pm 0.1$ & $2.5 \pm 0.6$ & 0.025 \\
\hline Operating time (minutes) & $10 \pm 0.7$ & $20.5 \pm 2.2$ & 0.043 \\
\hline Postoperative bleeding & 0 & 1 & \\
\hline Urinary retention & 0 & 1 & \\
\hline Anal stenosis & 0 & 0 & \\
\hline Anal incontinence & 0 & 0 & \\
\hline Postoperative pain 24 hours & $5.4 \pm 0.5$ & $6.8 \pm 1.2$ & 0.032 \\
\hline Postoperative pain 48 hours & $4.8 \pm 1.4$ & $6.5 \pm 1.2$ & 0.044 \\
\hline Postoperative pain 72 hours & $1.5 \pm 1.2$ & $4.1 \pm 0.6$ & 0.022 \\
\hline
\end{tabular}

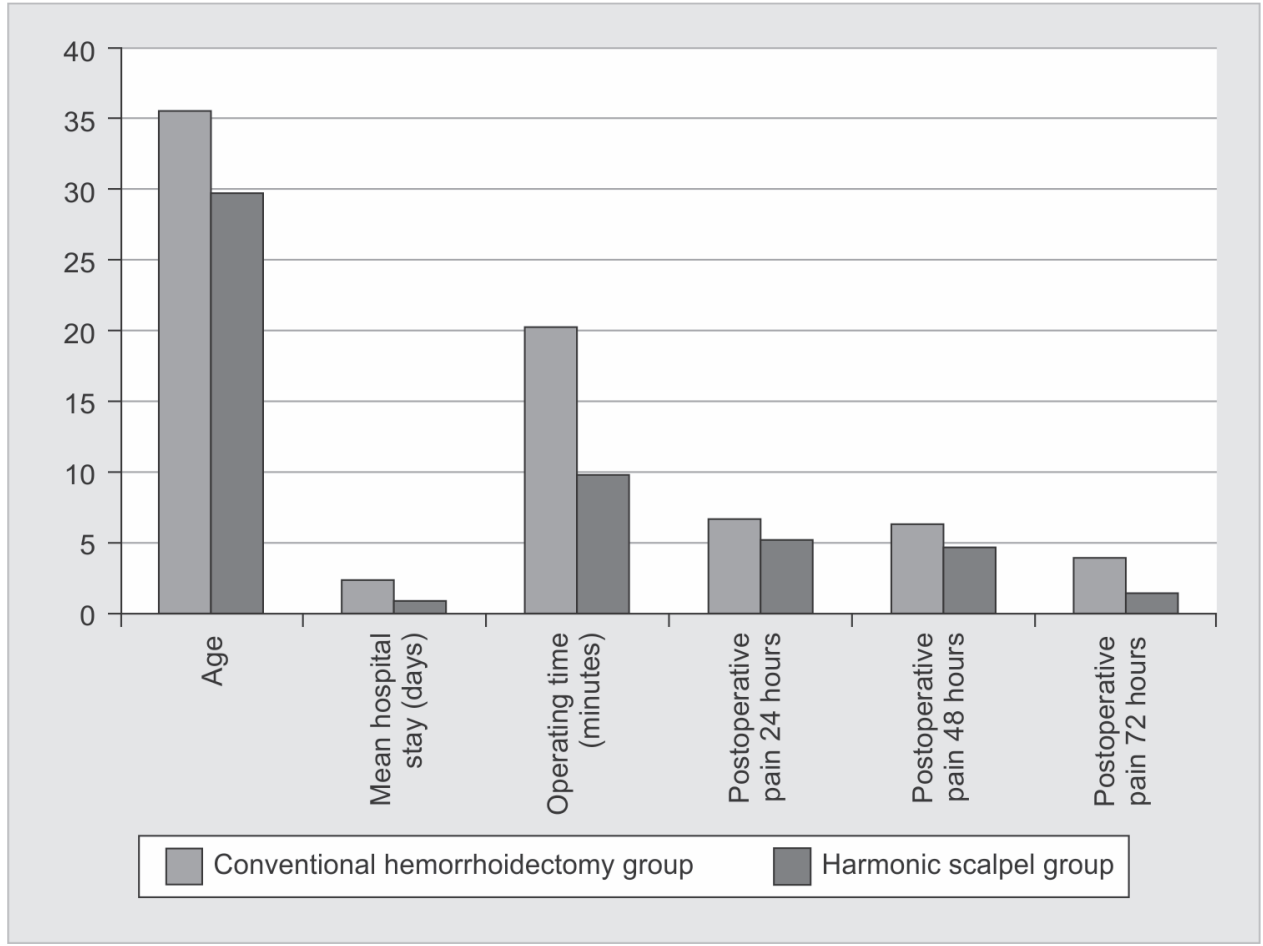

Fig. 1: Outcome of harmonic scalpel vs conventional hemorrhoidectomy 
postoperative pain and bleeding. ${ }^{6}$ Recently, hemorrhoidectomy done with newly developed equipment has been reported to result in less postoperative pain and bleeding, shorter operation times, and shorter hospital stays. ${ }^{7-10}$

The harmonic scalpel is an ultrasonically activated instrument with sound waves as its source of power, which vibrates at a rate of 55,000 times per second. It is known for its ability to coagulate small and medium-sized vessels; thus potentially it may minimize postoperative swelling and edema to the surrounding tissue. ${ }^{11}$ The harmonic scalpel possesses the unique advantage of causing very little lateral thermal injury: $<1.5 \mathrm{~mm}$ at the surgical site is translated into decreased postoperative pain. ${ }^{12}$

Pain following Milligan-Morgan procedure can be explained by positioning the ligature onto the vascular root of the hemorrhoid, while electrocautery and laser procedures cause significant heat damage to the sensitive perihemorrhoid area. Reduction of this heat is considered to be the main reason for decreasing the level of pain after harmonic scalpel hemorrhoidectomy. This study clearly demonstrates the superior pain control profile of harmonic scalpel in hemorrhoidectmy and less need for analgesics.

Another positive aspect of harmonic scalpel hemorrhoidectomy is good hemostasis. Harmonic scalpel has proved to be effective in larger blood vessels as explained by colorectal surgery. ${ }^{13}$

The harmonic scalpel hemorrhoidectomy requires patience for cutting tissues and for good hemostasis, since the ultrasonic scissors have a slower pace. It is important to avoid pulling the tissue during cutting. Pulling leads to cutting tissues without adequate hemostasis.

\section{Conclusion}

Harmonic scalpel hemorrhoidectomy is a safe and effective procedure with fewer complications compared to conventional hemorrhoidectomy. Long-term follow-up with larger-scale studies is required.

\section{References}

1. MacRae HM, Mcleod RS. Comparison of hemorrhoidal treatment modalities. A meta-analysis. Dis Colon Rectum 1995;38(7):687-694. DOI: 10.1007/BF02048023.

2. Moult HP, Aubert M, et al. Classical treatment of hemorrhoids. J Visc Surg 2014;12:9.

3. Fareed M, El-Awady S, et al. Randomized trial comparing Ligasure to closed Feguson hemorrhoidectomy. Tech Coloproctol 2009;13(3):243-246. DOI: 10.1007/s10151-009-0520-4.

4. Voutillainen PE, Haglund $\mathrm{CH}$. Ultrasonically activated shears in thyroidectomies: a randomized trial. Ann Surg 2000;231(3):322-328. DOI: 10.1097/00000658-200003000-00004.

5. Jayne DG, Botterill I, et al. Randomized clinical trial of Ligasure vs conventional diathermy for day-case hemorrhoidectomy. Br J Sur 2002;89(4):428-432. DOI: 10.1046/j.0007-1323.2002.02056.x.

6. Bulus $\mathrm{H}$, Tas $\mathrm{A}$, et al. Evaluation of two hemorrhoidectomy techniques: harmonic scalpel and Ferguson with electrocautery. Asian J Surg 2014;37(1):20-23. DOI: 10.1016/j.asjsur.2013.04.002.

7. Sgourakis G, Sotiropolos GC. Stapled vs Ferguson hemorrhoidectomy: is there any evidence-based information? Int J Colorectal Dis 2008;23(9):825-832. DOI: 10.1007/s00384-008-0502-4.

8. Gravie JF, Lehur PA, et al. Stapled hemorrhoidopexy vs MilliganMorgan procedure: a prospective, randomized, multicenter trial with 2-year postoperative follow up. Ann Surg 2005;242(1):29-35. DOI: 10.1097/01.sla.0000169570.64579.31.

9. Ascanelli S, Gregorio C. Long short and long term results of randomized, controlled, prospective trial. Chir Ital 2005;57:439-447.

10. Hetzer FH, Demartines N. Stapled vs excision hemorrhoidectomy: Long term results of a prospective randomized trial. Arch Surg 2002;137(3):337-340. DOI: 10.1001/archsurg.137.3.337.

11. McCarus SD. Physiologic mechanism of the ultrasonically activated scalpel. J Am Associ Gynecol Laparosc 1996;3(4):601-608. DOI: 10.1016/S1074-3804(05)80174-4.

12. Armstrong DN, Ambroze WL. Harmonic scalpel vs electrocautery hemorrhoidectomy: a prospective evaluation. Dis Colon Rectum 2001;44(4):558-564. DOI: 10.1007/BF02234329.

13. Msika S, Deroide G, et al. Harmonic Scalel in laparoscopic colorectal surgery. Dis Colon Rectum 2001;44(3):432-435. DOI: 10.1007/ BF02234745. 